\title{
Clinical characteristics of 15 female Japanese patients with partial lipodystrophy identified in a diabetic outpatient clinic
}

\author{
Iwanishi $M^{1}$, Kusakabe $T^{2}$, Azuma $C^{1}$, Tezuka $Y^{1}$, Yamamoto $Y^{1}$, Ito-Kobayashi $\mathbf{J}^{1}$, Washiyama $\mathbf{M}^{1}$ and Ebihara $\mathrm{K}^{3}$ \\ ${ }^{1}$ Department of Diabetes and Endocrinology, Kusatsu General Hospital 1660 Yabase, Kusatsu, Shiga 525-8585, Japan \\ ${ }^{2}$ Department of Endocrinology, Metabolism and Hypertension, Clinical Research Institute, National Hospital Organization Kyoto Medical Center 1-1 Fukakusa \\ Mukaihata-cho, Fushimi-ku, Kyoto 612-8555, Japan \\ ${ }^{3}$ Division of Endocrinology and Metabolism, Jichi Medical University 3311-1 Yakushiji, Shimotsuke, Tochigi 329-0498, Japan
}

\begin{abstract}
Background and objective: The present study aims to clarify the clinical characteristics of Japanese women with Partial Lipodystrophy (PL) in a diabetic outpatient clinic.

Methods: We performed visual and physical examinations on approximately 800 female patients who visited the diabetic outpatient clinic at Kusatsu General Hospital between August 2003 and August 2013. Following these examinations, we diagnosed PL using dual energy X-ray absorptiometry (DEXA) and magnetic resonance imaging (MRI). We performed a genetic analysis in eight patients with PL. We examined the usefulness of fat mass ratio (FMR) in diagnosing PL by comparing PL and Control groups.
\end{abstract}

Results: We identified 15 female Japanese patients with PL. Eight patients who received a genetic analysis had neither mutations in candidate genes known to be associated with familial partial lipodystrophy (FPLD) nor novel likely candidate causal genes. All patients had fat loss in the lower limbs, frequently accompanied by abdominal fat accumulation based on DEXA and MRI findings. As FPLD1 is usually autosomal dominant and is characterized by fat loss in the lower limbs with abdominal fat accumulation, a high rate of positivity for a family history, unknown genetic cause, and metabolic disturbances, we thought 8 patients who received a genetic analysis fitted into the category of FPLD1. Our patients with PL might be predisposed to develop diabetic microangiopathy, severe atherosclerosis, nonalcoholic steatohepatitis and malignancy. The cut-off point of FMR was 1.2 (sensitivity $100 \%$, specificity $91 \%$ ) to identify these patients.

Conclusions Patients with PL are more common than previously thought, and not a few patients of 15 patients with PL we identified might have FPLD1. FMR is a useful indicator of PL among Japanese women.

\section{Introduction}

Lipodystrophy has been classified as either an inherited or acquired general or partial loss of adipose tissue deposits [1-4]. It is commonly associated with dyslipidemia, hepatic steatosis, and insulin-resistant diabetes. However, Strickland, et al. reported a novel form of partial lipodystrophy (PL) of the limbs that does not resemble the entities that are conventionally categorized into the two-by-two classification of congenital versus acquired and generalized versus partial $[5,6]$. This lipodystrophy is characterized by symmetrical distal lipodystrophy of the limbs and severe insulin resistance and appears to be acquired based on a lack of a family history and onset in adulthood. Familial partial lipodystrophy (FPLD) is classified as an inherited partial lipodystrophy, comprising a clinically heterogeneous group of autosomal dominant disorders characterized by the variable loss of subcutaneous fat in the extremities. FPLD is also classified into eight subtypes, FPLD1-7 and AKT2-linked lipodystrophy $[1,2,7,8]$. On the other hand, acquired $\mathrm{PL}$ has varying etiology, including Barraquer-Simons syndrome, antiretroviral treatment for HIV infection, viral infection, autoimmune disease, and hematopoietic stem cell transplantation $[4,9,10]$.

PL is often underdiagnosed, and the American Association of Clinical Endocrinologists (AACE) has provided consensus recommendations for the detection of lipodystrophy for clinical practitioners [11]. Therefore, we sought a simple indicator to help clinical practitioners diagnose PL. Recently Valerio reported that fat mass ratio (FMR) determined using dual-energy X-ray absorptiometry (DEXA) is useful for the diagnosis of FPLD among 18 patients with FPLD, including 16 patients with FPLD2 [12]. FMR is the ratio of the percentage of trunk fat mass to the percentage of lower limb fat mass (FMR $=\%$ of trunk fat mass / \% of lower limb fat mass) [12-14]. We defined modified FMR as the ratio of trunk fat mass to lower limb fat mass (modified FMR $=$ trunk fat mass $/$ lower limb fat mass). We noticed some patients had decreased lean mass in the lower limbs, compared with a control group, resulting in an increase in \%fat in the lower limbs.

*Correspondence to: Masanori Iwanishi $\mathrm{PhD}, \mathrm{MD}$, Department of Diabetes and Endocrinology, Kusatsu General Hospital 1660 Yabase, Kusatsu, Shiga 5258585, Japan, Tel: 077-563-8866 Fax: 077-563-0520; E-mail: masa-iwani@solid. ocn.ne.jp

Key words: diabetic outpatient clinic, familial partial lipodystrophy 1 (FPLD1), fat mass ratio (FMR)

Received: January 25, 2019; Accepted: February 14, 2019; Published: February 18,2019 
Increased \%fat in lower limbs may cause a decrease in FMR, leading to underestimation of the severity of fat loss. Therefore, we examined the possibility of whether modified FMR is a better indicator than FMR for the diagnosis for FPLD. In addition, we performed a genetic analysis of eight patients with PL.

In this paper, we report the phenotype of lipodystrophy and the clinical characteristics of 15 patients with PL we identified in our diabetic outpatient clinic, including six patients with PL reported previously [15-18], and also report the usefulness of FMR and modified FMR in diagnosing PL in Japanese women.

\section{Materials and methods}

\section{Study subjects}

First author, Masanori Iwanishi performed visual and physical examinations on approximately 800 female patients who visited the diabetic outpatient clinic at Kusatsu General Hospital between August 2003 and August 2013. Following these examinations, we examined fat distribution in 23 patients who were suspected of having subcutaneous fat loss in some part of the body, using dual-energy X-ray absorptiometry (DEXA) and diagnosed PL based on symmetrical nearcomplete loss or complete loss of subcutaneous fat in peripheral sites as evaluated by magnetic resonance imaging (MRI). Patients with PL were categorized into subgroups of PL (inherited or acquired, FPLD17) based on clinical observations such as the onset of lipodystrophy, their family history, personal history, and genetic information. The PL group comprised 15 female PL patients from the diabetic outpatient clinic at Kusatsu General Hospital. A control group (Control 1) with 41 healthy female volunteers between 50 and 59 years of age was recruited from the employees of Tanita, Inc. Another control group (Control 2) with 139 healthy female volunteers between 29 and 80 years of age was also recruited from among the employees of Tanita. Inc. The mean body mass index (BMI) in Control groups 1 and 2 was $23.5 \mathrm{~kg} / \mathrm{m}^{2}$ and 25.4 $\mathrm{kg} / \mathrm{m}^{2}$, respectively. We evaluated the body composition as determined by DEXA in PL patients using the Control 1 and Control 2 groups with their different mean BMI values. A control group with 19 healthy volunteers was matched for age, sex, and BMI with the PL group. This group was recruited from employees of Tanita, Inc., and who were not related to the patients. This study (approved on 2 September 2016, approval number: 2016090203), including whole-exome sequencing (approved on 12 December 2016, approval number: 2016120206), was approved by the Ethics Committee of Kusatsu General Hospital. The patients agreed to participate in the study and provided their verbal informed consent.

\section{Methods}

\section{Blood samples and biochemical analyses}

Blood was collected after a 12-h overnight fast for the analysis of glucose, insulin, leptin, and adiponectin. Plasma glucose, hemoglobin A1c (HbA1c), serum insulin level, serum leptin level, and serum adiponectin level were measured as reported previously [15-18]. Serum leptin and adiponectin levels were measured before thiazolidinediones (TZDs) were administered to the patients.

\section{DEXA}

Whole-body DEXA was performed with a multiple detector fanbeam Hologic QDR-4500W densitometer (Hologic, Marlborough, USA) in the PL group and with a multiple detector fan-beam GE Lunar DPXL densitometer (General Electric, Fairfield, USA) in the control groups. The FMR is the ratio of the percentage of trunk fat mass to the percentage of lower limb fat mass $(\mathrm{FMR}=\%$ of trunk fat mass $/ \%$ of lower limb fat mass) [12-14]. We defined a modified FMR as the ratio of trunk fat mass to lower limb fat mass (modified FMR= trunk fat mass / lower limb fat mass).

\section{MRI}

MRI was performed using a 3.0 Tesla imaging device (Sigma Horizon; General Electric).

\section{Measurement of the visceral fat area}

Subcutaneous and visceral fat areas were measured using a modified computed tomography method (Light Speed Plus-R,-; General Electric) by Tokunaga, et al. at the umbilical level [19].

\section{Sequence analyses}

We obtained written informed consent for genetic analyses from the patients who underwent genetic analyses. We examined the sequences of the entire coding region and exon-intron boundary regions of LMNA, PPARG, AKT2, and Caveolin-1 in Patient 1, LMNA, PPARG and Caveolin-1 in Patient 2, using methods reported previously [1518], and whole exome sequencing was performed for Patients $3,4,5$, 8 , 12 , and 14 , as reported previously [15].

\section{Statistical analysis}

The values are expressed as the mean \pm standard deviation (SD) [20]. The differences were analyzed using a paired Students $t$-test. Statistical analysis was performed with statistical software EZR [21]. P-values of less than 0.05 were considered significant. The sensitivity and specificity of FMR in patients with FPLD were calculated using receiver operating characteristic (ROC) curve analysis.

\section{Results}

\section{Clinical characteristics of 15 patients with PL}

Based on DEXA, MRI findings, and clinical observations, we diagnosed 15 women with PL among approximately 800 female patients who visited the diabetic outpatient clinic at Kusatsu General Hospital between August 2003 and August 2013. The basal characteristics of the 15 patients with PL are shown in table 1 , and their clinical characteristics are shown in table 2. The basal and clinical characteristics of Patients $1,2,3,5,8$, and 12 were reported previously [15]. The mean age at the diagnosis of lipodystrophy was 58.0 years. The mean age at the diagnosis of diabetes was 44.3 years and the mean duration of diabetes was 15.3 years. The mean BMI was $25.7 \mathrm{~kg} / \mathrm{m}^{2}$. The mean $\mathrm{HbAlc}$ was $7.6 \%$. Fourteen patients were diagnosed with diabetes, but one patient (Patient 10) exhibited normal glucose tolerance. According to the interview, all patients noticed fat loss in their lower limbs during childhood or adolescence and eleven patients likely had autosomal dominant inheritance of lipodystrophy. Four patients (Patients 4, 6, 7, and 15) did not have a family history of lipodystrophy.

\section{Fat distribution in 15 patients with PL}

DEXA study results are presented in table 3. All patients except for Patient 10 had a decreased lower limb fat mass compared with Control group 1, which had a mean BMI value of $23.5 \mathrm{~kg} / \mathrm{m}^{2}$. Patient 10 had a BMI of $32.0 \mathrm{~kg} / \mathrm{m}^{2}$ and had a decreased lower limb fat mass compared with the Control 2 group, which had a mean BMI value of $25.4 \mathrm{~kg} / \mathrm{m}^{2}$. The locations of lipoatrophy and fat deposition on MRI are presented in Table 2. Phenotypical features of five patients (Patients 1, 2, 3, 5, and 12) with PL, reported previously [15-18] are shown in Figure 1. The results 
Table 1. Basal characteristics of the patients with partial lipodystrophy

\begin{tabular}{|c|c|c|c|c|c|c|c|c|c|c|c|c|c|c|}
\hline Patient & $\begin{array}{c}\text { Age } \\
\text { (Years) }\end{array}$ & $\begin{array}{l}\text { DM age } \\
\text { of onset } \\
\text { (Years) }\end{array}$ & $\begin{array}{c}\text { BMI (kg/ } \\
\left.\mathbf{m}^{2}\right)\end{array}$ & $\begin{array}{c}\text { HbA1c } \\
(\%)\end{array}$ & $\begin{array}{l}\text { Plasma } \\
\text { glucose } \\
(\mathrm{mg} / \mathrm{dL})\end{array}$ & $\begin{array}{l}\text { Plasma } \\
\text { insluin } \\
(\mu \mathrm{U} / \mathrm{mL})\end{array}$ & $\begin{array}{c}\text { Serum } \\
\text { cholestrol } \\
(\mathrm{mg} / \mathrm{dL})\end{array}$ & $\begin{array}{c}\text { Serum } \\
\text { triglyceride } \\
(\mathbf{m g} / \mathbf{d L})\end{array}$ & \begin{tabular}{|c|} 
Serum \\
HDL \\
choleserol \\
(mg/dL)
\end{tabular} & $\operatorname{AST}(\mathbf{u} / \mathbf{L})$ & $\operatorname{ALT}(\mathbf{u} / \mathbf{L})$ & $\begin{array}{c}\text { PLTS } \\
\left(10^{4} / \mu \mathrm{L}\right)\end{array}$ & $\begin{array}{c}\text { Serum } \\
\text { leptin }(n g / \\
m L)\end{array}$ & $\begin{array}{c}\text { Serum } \\
\text { Adiponectin } \\
(\mathrm{ug} / \mathrm{mL})\end{array}$ \\
\hline 1 & 46 & 34 & 22.9 & 12.0 & 245.0 & 17.7 & 200.0 & 137.0 & 49.0 & 12.0 & 10.0 & 27.4 & 10.4 & 7.9 \\
\hline 2 & 48 & 35 & 30.0 & 6.9 & ND & ND & 211.0 & 755.0 & 34.0 & 29.0 & 41.0 & 29.6 & 36.1 & 7.1 \\
\hline 3 & 47 & 33 & 27.6 & 9.3 & ND & ND & 266.0 & 171.0 & 65.0 & 13.0 & 13.0 & 34.0 & 6.2 & 2.3 \\
\hline 4 & 39 & 20 & 27.7 & 7.9 & 165.0 & 13.5 & 240.0 & 263.0 & 55.0 & 19.0 & 18.0 & 19.0 & 17.1 & 3.1 \\
\hline 5 & 69 & 60 & 25.5 & 6.6 & 98.0 & 7.9 & 173.0 & 157.0 & 51.0 & 18.0 & 27.0 & 38.2 & ND & ND \\
\hline 6 & 59 & 56 & 26.1 & 7.6 & 146.0 & 10.5 & 213.0 & 139.0 & 57.0 & 44.0 & 72.0 & 18.2 & ND & ND \\
\hline 7 & 62 & 59 & 21.4 & 8.0 & 205.0 & 3.9 & 235.0 & 112.0 & 60.0 & 18.0 & 12.0 & 36.5 & ND & ND \\
\hline 8 & 50 & 41 & 22.2 & 6.5 & 127.0 & 12.8 & 177.0 & 79.0 & 46.0 & 25.0 & 37.0 & 17.7 & 4.9 & 4.1 \\
\hline 9 & 58 & 30 & 22.1 & 6.3 & ND & ND & 160.0 & 56.0 & 64.0 & 13.0 & 9.0 & 16.6 & ND & ND \\
\hline 10 & 35 & ND & 32.0 & 5.1 & 88.0 & 9.2 & 206.0 & 62.0 & ND & 27.0 & 20.0 & 16.3 & 36.2 & 8.2 \\
\hline 11 & 70 & 30 & 24.4 & 8.8 & ND & ND & 115.0 & 237.0 & 31.0 & 14.0 & 10.0 & 11.9 & 37.1 & 4.7 \\
\hline 12 & 67 & 47 & 25.2 & 8.4 & 95.0 & 8.8 & 181.0 & 92.0 & 56.0 & 45.0 & 34.0 & 23.9 & 12.1 & 8.1 \\
\hline 13 & 81 & 77 & 26.8 & 5.3 & ND & ND & 189.0 & 80.0 & 47.0 & 22.0 & 13.0 & 17.8 & 16.0 & 13.5 \\
\hline 14 & 65 & 30 & 26.7 & 8.0 & ND & ND & 140.0 & 74.0 & 42.0 & 16.0 & 14.0 & 15.5 & 13.5 & 2.9 \\
\hline 15 & 74 & 68 & 24.9 & 7.7 & ND & ND & 174.0 & 84.0 & 78.0 & 20.0 & 15.0 & 17.7 & ND & ND \\
\hline $\begin{array}{l}\text { Mean } \\
\text { value }\end{array}$ & 58.0 & 44 & 25.7 & 7.6 & 146.1 & 10.5 & 192.0 & 166.5 & 52.5 & 22.3 & 23.0 & 22.7 & 19.0 & 6.2 \\
\hline SD value & 13.4 & 17 & 3.0 & 1.7 & 56.4 & 4.2 & 39.1 & 174.1 & 12.5 & 10.4 & 17.1 & 8.4 & 12.7 & 3.4 \\
\hline Number & 15 & 14 & 15 & 15 & 8 & 8 & 15 & 15 & 14 & 15 & 15 & 15 & 10 & 10 \\
\hline
\end{tabular}

SD: Standard Deviation; AST: Aspartate transaminase; ALT: Alanine transaminase; PLTS: Platelets; ND: Not determined

Table 2. Clinical Characteristics of the Patients with partial lipodystrophy

\begin{tabular}{|c|c|c|c|c|c|c|c|c|c|}
\hline Patient & Clinical Lipoatrophy & $\begin{array}{l}\text { Fat } \\
\text { Deposition }\end{array}$ & Family History & $\begin{array}{l}\text { Visceral } \\
\text { Fat } \\
\text { Area } \\
\left(\mathrm{cm}^{2}\right)\end{array}$ & GA & DR & albuminuria & $\begin{array}{l}\text { eGFR }(\mathrm{mL} / \\
\left.\mathrm{min} / 1.73 \mathrm{~m}^{2}\right)\end{array}$ & Clinical Observation \& Therapy \\
\hline 1 & calves, thighs, buttocks & Trunk & mother, two sisters & 83.3 & $(+)$ & MI & $\mathrm{N}$ & 71.0 & $\begin{array}{l}\text { Relatively severe insulin resistance INS, TZDs } \\
\text { (remarkable efficacy) }\end{array}$ \\
\hline 2 & $\begin{array}{l}\text { calves, thighs, buttocks, } \\
\text { forearms }\end{array}$ & Trunk & mother & 140.4 & $(+)$ & MI & Macro & 8.8 & Cerebral infraction, HT, Chronic renal failure INS, TZDs \\
\hline 3 & $\begin{array}{l}\text { calves, thighs, buttocks, } \\
\text { forearms }\end{array}$ & Trunk & mother & 119.0 & $(+)$ & MI & $\mathrm{N}$ & 106.0 & $\begin{array}{l}\text { Middle cerebral artery occlusion follicular lymphoma } \\
\text { IHD, INS, TZDs }\end{array}$ \\
\hline 4 & calves, thighs, buttocks & Trunk & unknown & 103.6 & $(+)$ & MI & Macro & 72.0 & RA, Ovarian tumor, HT SU, BG, TZDs \\
\hline 5 & $\begin{array}{l}\text { calves, thighs, buttocks, } \\
\text { forearms }\end{array}$ & Trunk & $\begin{array}{l}\text { mother, brother, } \\
\text { sister }\end{array}$ & 126.0 & $(+)$ & $(-)$ & $\mathrm{N}$ & 70.6 & $\begin{array}{l}\text { Cerebral infraction, HT, IHD Middle cerebral artey } \\
\text { occlusion SU, TZDs }\end{array}$ \\
\hline 6 & calves, thighs & Trunk & unknown & ND & & $(-)$ & Micro & 81.1 & NAFLD, HT DPP4I, TZDs \\
\hline 7 & calves, thighs & & unknown & 75.3 & & $(-)$ & $\mathrm{N}$ & 76.0 & Renal Pelvic carcinoma, HT INS, TZDs \\
\hline 8 & $\begin{array}{l}\text { calves, thighs, buttocks, } \\
\text { forearms }\end{array}$ & & mother & 124.0 & $(+)$ & S & Macro & 123.0 & ASO, Severe insulin resistence, HT GLP-IRA \\
\hline 9 & calves, thighs & Trunk & father & ND & & $(-)$ & $\mathrm{N}$ & 80.7 & Cerebral infraction, HT, INS, TZds \\
\hline 10 & calves, thighs & $\begin{array}{l}\text { Trunk, } \\
\text { neck }\end{array}$ & mother & 83.0 & & ND & ND & ND & Colon cancer \\
\hline 11 & $\begin{array}{l}\text { calves, thighs, buttocks, } \\
\text { forearms }\end{array}$ & Trunk & mother, sister & 121.2 & & S & Macro & 20.9 & Chronic renal failure, HT DPP4I, TZDs \\
\hline 12 & calves, thighs, buttocks & Trunk & mother, sister & 160.2 & $(+)$ & $(-)$ & $\mathrm{N}$ & 58.8 & $\begin{array}{l}\text { Liver cirrhosis probably due to NASH Gastric cancer, } \\
\text { HT, SU, TZDs }\end{array}$ \\
\hline 13 & calves, thighs, buttocks & Trunk & daughter & 247.5 & & MI & Macro & 49.2 & HT INS \\
\hline 14 & calves, thighs & Trunk & mother, son & 152.9 & $(+)$ & $\mathrm{S}$ & Micro & 94.9 & HT, IHD INS: High dose insulin injection \\
\hline 15 & calves, thighs & Trunk & unknown & 109.3 & & $(-)$ & $\mathrm{N}$ & 43.1 & $\begin{array}{l}\text { Cerebral infraction, Narrowing of middle cerebral artey, } \\
\text { HT, INS, TZDs }\end{array}$ \\
\hline
\end{tabular}

IHD: Ischemic Heart Disease; RA: Rheumatoid Arthritis; NAFLD: Non-alcoholic Fatty Liver Disease; NASH: Non-alcoholic steatohepatitis; ASO: Arteriosclerosis Obliterans; INS: Insulin; TZD: hiazolidinediones: SU: Sulfonyl Urea; BG: Biguanide; DPP4I: DPP4 Inhibitor; GLP-1RA: GLP-1 Receptor Agonist; NGT: Normal Glucose Tolerance; ND: Not Determined; HT: Hypertension; GA: Genetic Analysis; DR: Diabetic Retinopathy; MI: Mild non-proliferative diabetic retinopathy; S: Server non-proliferative diabetic retinopathy; DN: Diabetic Nephropathy; N: Normal Albuminuria; Micro: Micro albuminuria; Macro: Macro albuminuria

of MRI assessments of body fat distribution in Control subjects and Patient 2 are shown in figure 1. The results of MRI assessments of body fat distribution in Patient 2 were reported previously [15]. Compared with the control subjects, Patient 2 had severe subcutaneous fat loss in the buttocks, the antero-lateral and posterior thigh region, the entire circumference of the calf, and the antero-lateral and posterior forearms. As shown in figure S1 and figure S2, all patients had near-complete loss of subcutaneous fat, particularly in the antero-lateral and posterior thigh region and the calf region.

As shown in table 2, almost all patients had excess fat in the trunk (Patients 1-6, and 9-15). Thus, based on MRI and DEXA findings, subcutaneous fat loss in the lower limbs with excess truncal fat was predominant in this set of female Japanese patients with PL. 


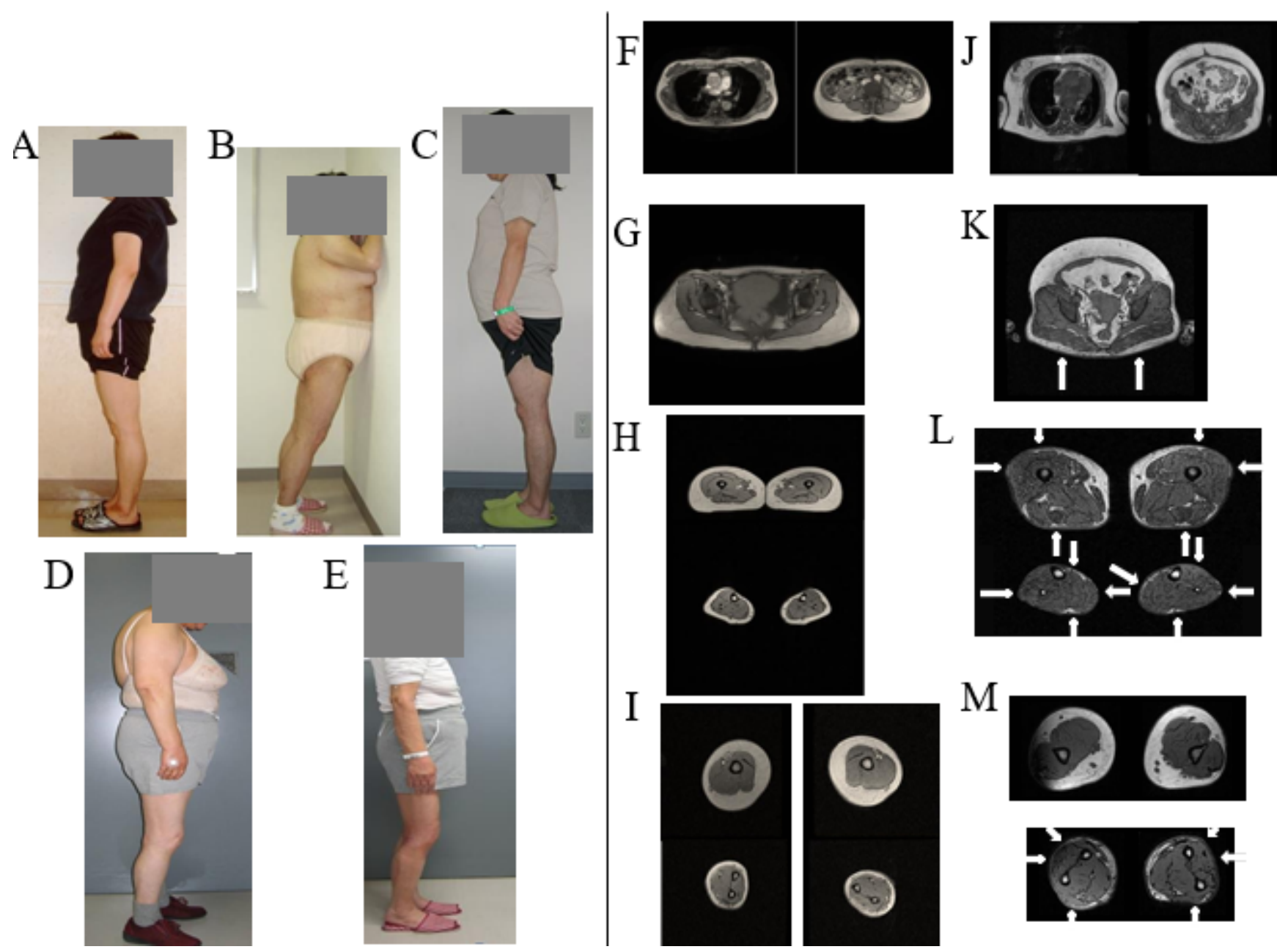

Figure 1. The phenotypic features of 5 patients with PL reported previously are shown. A: Patient 1 was a 46 -year-old woman with BMI of 22.9 kg/m2. B: Patient 2 was a 48 -year-old woman with BMI of $30.0 \mathrm{~kg} / \mathrm{m} 2$. C: Patient 3 was a 47 -year-old woman with BMI of $27.6 \mathrm{~kg} / \mathrm{m} 2$. D: Patient 5 was a $69-$ year-old woman with BMI of $25.5 \mathrm{~kg} / \mathrm{m} 2$. E: Patient 12 was a $67-$ yearold woman with BMI of $25.2 \mathrm{~kg} / \mathrm{m} 2$. They had loss of subcutaneous fat deposits in the lower limbs and buttocks with lower limb musculature. Patients $1,2,3$, and 5 had excess fat deposition in the trunk. The results of MRI assessments of body fat distribution in a control subject and Patient 2 are shown in F-I, and J-M, respectively. The (healthy) control subject was a 56-year-old woman (height $152.0 \mathrm{~cm}$; weighed $52.0 \mathrm{~kg}$; BMI $22.5 \mathrm{~kg} / \mathrm{m} 2$ ). F, J Thoracic MRI scans at the level of the seventh thoracic vertebrae (left panel) and abdominal MRI scans at the umbilical level (right panel). G, K T1-weighted MRI scans at the middle level of the gluteus. H, L MRI scans at the middle level of the thigh (H: upper panel, L: upper panel) and calf (H: lower panel, L lower panel). I, M MRI scans at the middle level of the right arm (I: upper left panel, M: upper left panel) and left arm (I: upper right panel, M: upper right panel). I, M MRI scans at the middle level of the right forearm (I: lower left panel, M: lower left panel) and left forearm (I: lower right panel, M: lower right panel). The control subject had preserved subcutaneous fat around the entire circumference of the thigh, calf, arm and forearm. Compared with the control subject, Patient 2 had severe subcutaneous fat loss in the buttocks (K), antero-lateral and posterior thigh region (Upper panel of L), entire circumference of the calf (Lower panel of L), and antero-lateral and posterior forearms (Lower panel of M), as indicated by arrows

\section{Complications in 15 patients with PL}

As shown in table 2, the visceral fat area at the umbilical level was $100 \mathrm{~cm}^{2}$ or more in $67 \%$ of patients, $80 \%$ of patients had hypertension, and seven patients (Patients 2, 3, 5, 8, 9, 14, and 15) had severe atherosclerosis (Cerebral infarction in four cases, ischemic heart disease in three cases, arteriosclerosis obliterans in one case, and middle cerebral artery occlusion in two cases). We observed malignancy in four of 15 patients (Patient 3: follicular lymphoma, Patient 7: renal pelvic carcinoma, Patient 10: colon cancer, Patient 12: gastric cancer) during the follow-up period. Patients 2 and 11 had chronic renal failure due to diabetic nephropathy. Patients 4, 8, and 13 had overt nephropathy, and Patients 6 and 14 had microalbuminuria. Patients 1, 2, 3, 4, and 13 had mild non-proliferative diabetic retinopathy, whereas Patients 8,11 , and 14 had severe non-proliferative diabetic retinopathy. No patients had overt diabetic neuropathy with neurological symptoms. Patient $12 \mathrm{had}$ liver cirrhosis or pre-cirrhosis.

\section{Sequence analyses}

We examined the sequences of the entire coding region and exonintron boundary regions of LMNA, PPARG, AKT2, and Caveolin-1 in Patient 1, and LMNA, PPARG, and Caveolin-1 in Patient 2. We found no mutations in these genes in these patients. Whole-exome sequencing in Patients 3, 4, 5, 8, 12, and 14 showed no mutations in candidate genes known to be associated with FPLD. In addition, no novel likely candidate causal genes were found in these analyses.

Comparison of DEXA measurements between patients in PL and control groups, and effectiveness of FMR in diagnosing $\mathrm{PL}$ in Japanese women

A control group with 19 healthy volunteers was matched for age, sex, and BMI with the PL group. The comparison of the control and PL groups is detailed in table 4. Although age and BMI were matched, the PL group had significant differences in fat distribution, as evaluated by 
Table 3. Body composition as determined by DEXA in patients with Partial Lipodystrophy. The Means \pm SD in Patient, control 1 and control 2 are in the bottom 3 sections. The figures in parentheses are SD. normal values in control 1 were obtained from 41 healthy women between the ages of 50 and 59 years. Normal values in control 2 were obtained from 139 healthy women between the ages of 29 and 80 years.

\begin{tabular}{|c|c|c|c|c|c|c|c|c|c|c|c|c|c|c|c|c|}
\hline Patient & $\begin{array}{c}\text { Age } \\
\text { (Years) }\end{array}$ & $\begin{array}{c}\text { BMI (kg/ } \\
\left.\mathbf{m}^{2}\right)\end{array}$ & $\begin{array}{c}\text { Total Fat } \\
(\%)\end{array}$ & $\begin{array}{c}\text { Upper } \\
\text { Limbs } \\
\% \text { Fat } \\
(\%)\end{array}$ & $\begin{array}{c}\text { Trunk } \\
\% \text { Fat } \\
(\%)\end{array}$ & $\begin{array}{c}\text { Lower } \\
\text { Limbs } \\
\text { \%Fat(\%) }\end{array}$ & $\begin{array}{c}\text { Total Fat } \\
\text { Mass } \\
(\mathrm{kg})\end{array}$ & $\begin{array}{c}\text { Upper } \\
\text { Limb } \\
\text { Fat Mass } \\
\text { (kg) }\end{array}$ & $\begin{array}{c}\text { Trunk } \\
\text { Fat Mass } \\
\text { (kg) }\end{array}$ & $\begin{array}{c}\text { Lower } \\
\text { Limbs } \\
\text { Fat Mass } \\
\text { (kg) }\end{array}$ & $\begin{array}{c}\text { Total } \\
\text { Lean } \\
\text { Mass } \\
(\mathbf{k g})\end{array}$ & $\begin{array}{c}\text { Upper } \\
\text { Limbs } \\
\text { Lean } \\
\text { Mass } \\
(\mathbf{k g}) \\
\end{array}$ & $\begin{array}{c}\text { Trunk } \\
\text { Lean } \\
\text { Mass } \\
\text { (kg) }\end{array}$ & $\begin{array}{c}\text { Lower } \\
\text { Limbs } \\
\text { Lean } \\
\text { Mass } \\
\text { (kg) }\end{array}$ & FMR & $\begin{array}{c}\text { Modified } \\
\text { FMR }\end{array}$ \\
\hline 1 & 46 & 22.9 & 33.1 & 44.6 & 40.4 & 12.3 & 20.2 & 2.7 & 15.0 & 1.7 & 38.8 & 3.3 & 21.5 & 10.9 & 3.3 & 8.8 \\
\hline 2 & 48 & 30.0 & 32.1 & 43.8 & 37.9 & 15.1 & 21.3 & 3.1 & 15.0 & 2.3 & 42.4 & 3.3 & 23.9 & 12.0 & 2.5 & 6.5 \\
\hline 3 & 47 & 27.6 & 28.2 & 28.5 & 36.1 & 12.1 & 18.2 & 1.8 & 13.3 & 2.4 & 44.1 & 3.8 & 22.9 & 14.7 & 3.0 & 5.5 \\
\hline 4 & 39 & 27.7 & 29.3 & 43.0 & 32.2 & 24.8 & 19.3 & 3.1 & 10.9 & 4.2 & 43.2 & 3.6 & 22.3 & 13.1 & 1.3 & 2.6 \\
\hline 5 & 69 & 25.5 & 36.8 & 52.5 & 40.1 & 26.1 & 22.1 & 4.0 & 13.5 & 3.9 & 36.5 & 3.5 & 20.0 & 10.1 & 1.5 & 3.5 \\
\hline 6 & 59 & 26.1 & 29.3 & 38.9 & 32.8 & 24.5 & 18.5 & 2.9 & 10.4 & 4.3 & 42.5 & 4.6 & 20.9 & 13.5 & 1.3 & 2.4 \\
\hline 7 & 62 & 21.4 & 23.7 & 27.0 & 27.8 & 17.3 & 11.2 & 1.3 & 6.8 & 2.3 & 34.7 & 3.3 & 17.3 & 10.6 & 1.6 & 3.0 \\
\hline 8 & 50 & 22.2 & 25.2 & 29.1 & 26.1 & 22.0 & 13.7 & 1.6 & 7.9 & 3.5 & 38.9 & 3.5 & 21.8 & 10.4 & 1.2 & 2.3 \\
\hline 9 & 58 & 22.1 & 37.6 & 47.9 & 40.4 & 31.8 & 19.2 & 2.6 & 11.3 & 4.6 & 30.5 & 2.6 & 16.3 & 8.5 & 1.3 & 2.5 \\
\hline 10 & 35 & 32.0 & 44.8 & 56.3 & 52.5 & 30.7 & 34.5 & 5.2 & 22.0 & 6.4 & 40.1 & 3.8 & 19.2 & 13.5 & 1.7 & 3.4 \\
\hline 11 & 70 & 24.4 & 31.0 & 37.4 & 36.1 & 21.7 & 15.4 & 2.0 & 10.2 & 2.4 & 32.9 & 3.0 & 17.6 & 9.0 & 1.7 & 4.3 \\
\hline 12 & 67 & 25.2 & 31.1 & 40.2 & 35.6 & 21.6 & 17.4 & 2.5 & 10.6 & 3.4 & 36.9 & 3.6 & 18.7 & 10.8 & 1.6 & 3.1 \\
\hline 13 & 81 & 26.8 & 33.3 & 41.8 & 38.1 & 24.7 & 19.1 & 2.6 & 12.2 & 3.6 & 37.0 & 3.6 & 19.4 & 10.9 & 1.5 & 3.4 \\
\hline 14 & 65 & 26.7 & 31.2 & 42.2 & 35.4 & 23.9 & 19.2 & 2.9 & 11.9 & 3.8 & 40.5 & 4.0 & 21.1 & 12.5 & 1.5 & 3.1 \\
\hline 15 & 74 & 24.9 & 32.1 & 46.0 & 36.1 & 22.4 & 18.5 & 3.5 & 10.7 & 3.6 & 38.0 & 4.2 & 18.6 & 11.9 & 1.6 & 3.0 \\
\hline $\begin{array}{l}\text { Patient } \\
(\mathrm{n}=15)\end{array}$ & $58.0(13.4)$ & $25.7(3.0)$ & $32.0(5.1)$ & $41.3(8.4)$ & $36.5(6.1)$ & $22.1(5.8)$ & $19.2(5.1)$ & $2.8(1.0)$ & $12.1(36)$ & $3.5(1.2)$ & 38.5 (3.9) & $3.6(0.5)$ & $20.1(2.2)$ & $11.5(1.7)$ & $1.8(0.6)$ & $3.8(1.8)$ \\
\hline $\begin{array}{c}\text { Control } 1 \\
(n-41)\end{array}$ & $55.2(3.1)$ & $23.5(2.9)$ & $31.4(6.5)$ & $29.6(7.8)$ & $31.2(7.6)$ & $32.5(6.2)$ & $17.3(5.3)$ & $1.6(0.3)$ & $8.0(2.9)$ & $6.5(0.9)$ & $34.6(3.0)$ & $3.4(0.3)$ & $16.3(1.7)$ & $12.3(0.7)$ & & \\
\hline $\begin{array}{c}\text { Control } 2 \\
(n=139)\end{array}$ & $52.8(12.7)$ & $25.4(3.3)$ & $34.9(6.1)$ & $32.4(7.2)$ & $34.4(7.5)$ & $36.1(5.7)$ & $20.9(5.7)$ & $1.8(0.6)$ & $9.5(3.2)$ & $8.0(2.3)$ & $35.7(3.3)$ & $3.4(0.5)$ & $16.8(1.7)$ & $13.1(1.8)$ & $1.0(0.2)$ & $1.2(0.4)$ \\
\hline
\end{tabular}

Table 4. Comparison of DEXA measurements between patients with patients with Partial Lipodystrophy and control group

\begin{tabular}{|l|c|c|c|}
\hline & $\begin{array}{c}\text { Control } \\
(\mathbf{n = 1 9 )}\end{array}$ & PL (n=15) & P \\
\hline Age(years) & $57.0 \pm .12 .5$ & $58.0 \pm 13.4$ & 0.82 \\
\hline BMI (kg/m $\left.{ }^{2}\right)$ & $25.6 \pm 2.1$ & $25.7 \pm 3.0$ & 0.91 \\
\hline Total Fat (\%) & $35.5 \pm 4.0$ & $32.0 \pm 5.1$ & $<0.05$ \\
\hline Upper Limbs \%Fat & $32.9 \pm 5.0$ & $41.3 \pm 8.4$ & $<0.001$ \\
\hline Trunk \%Fat & $36.6 \pm 4.3$ & $36.5 \pm 6.1$ & 0.96 \\
\hline Lower Limbs \%Fat & $35.0 \pm 5.2$ & $22.1 \pm 5.8$ & $<0.001$ \\
\hline Total fat Mass (kg) & $21.1 \pm 3.9$ & $19.2 \pm 5.1$ & 0.23 \\
\hline Upper Limbs Fat Mass (kg) & $1.9 \pm 0.7$ & $2.8 \pm 1.0$ & $<0.01$ \\
\hline Trunk Fat Mass (kg) & $10.2 \pm 2.1$ & $12.1 \pm 3.6$ & 0.06 \\
\hline Lower Limbs Fat Mass (kg) & $7.6 \pm 2.1$ & $3.5 \pm 1.2$ & $<0.001$ \\
\hline Fat Mass Ratio (FMR) & $1.1 \pm 0.1$ & $1.8 \pm 0.6$ & $<0.001$ \\
\hline Modified Fat Mass Ratio (Modified FMR) & $1.4 \pm 0.4$ & $3.8 \pm 1.8$ & $<0.001$ \\
\hline Total Lean Mass (kg) & $35.8 \pm 3.3$ & $38.5 \pm 3.9$ & $<0.05$ \\
\hline Upper Limbs Lean Mass (kg) & $3.4 \pm 0.5$ & $3.6 \pm 0.5$ & 0.26 \\
\hline Trunk Lean Mass (kg) & $16.8 \pm 1.3$ & $20.1 \pm 2.2$ & $<0.001$ \\
\hline Lower Limbs Lean Mass (kg) & $13.1 \pm 2.0$ & $11.5 \pm 1.7$ & $<0.05$ \\
\hline
\end{tabular}

DEXA. Lower limb fat\% and lower limb fat mass in the PL group were significantly lower compared with the control group ( $22.1 \pm 5.8$ vs 35.0 $\pm 5.2, \mathrm{P}<0.001 ; 3.5 \pm 1.2$ vs $7.6 \pm 2.1, \mathrm{P}<0.001$ respectively). On the other hand, upper limb fat\% and upper limb fat mass in the PL group were significantly higher compared with the control group $(41.3 \pm 8.4$ vs $32.9 \pm 5.0, \mathrm{P}<0.001 ; 2.8 \pm 1.0$ vs $1.9 \pm 0.7, \mathrm{P}<0.001$, respectively). The trunk fat mass in the PL group was not significantly higher but tended to be high compared with the control group $(12.1 \pm 3.6$ vs $10.2 \pm 2.1$, $\mathrm{P}=0.06$ ). Total lean mass and trunk lean mass in the PL group were significantly higher compared with the control group (38.5 \pm 3.9 vs 35.8 $\pm 3.3 \mathrm{P}<0.05 ; 20.1 \pm 2.2$ vs $16.8 \pm 1.3 \mathrm{P}<0.001$ respectively). Lower limb lean mass in the PL group was significantly lower compared with that of the control group $(11.5 \pm 1.7$ vs $13.1 \pm 2.0, \mathrm{P}<0.05)$.
We compared FMR and modified FMR in our patients with those in healthy women. As shown in table 4, FMR and modified FMR in our patients were increased compared with the control group (1.8 \pm 0.6 vs $1.1 \pm 0.1 \mathrm{P}<0.001 ; 3.8 \pm 1.8$ vs $1.4 \pm 0.4 \mathrm{P}<0.001$ respectively). We evaluated receiver operating characteristic (ROC) curves and cut-off value of FMR for diagnosis of PL by comparing the PL group $(n=15)$ with the Control 2 group $(n=139)$. The optimal cut-off value of FMR was 1.2 with a sensitivity of $100 \%$ and a specificity of $91 \%$ for the diagnosis of PL. We also examined the optimal cut-off value of modified FMR using ROC curves. The optimal cut-off value of the modified FMR was 2.3 , with a sensitivity of $100 \%$ and a specificity of $99 \%$ for the diagnosis of PL. The area under the curve (AUC) of the ROC curve for FMR was 0.991 (95\% confidence interval [CI]: 0.98-1.00), whereas the AUC for the modified FMR was 0.9998 (95\% CI: 0.9991-1.00). Examining the statistical significance based on these values, we found that there was no significant difference $(\mathrm{P}=0.115)$ in the usefulness between FMR and modified FMR.

\section{Discussion}

Lipodystrophy is a condition characterized by regional or total selective loss or absence of subcutaneous fat in the absence of nutritional deprivation or catabolic state. The core finding for the diagnosis of lipodystrophy is the loss or absence of subcutaneous fat in a partial or generalized fashion. We demonstrated symmetrical near-complete loss in the antero-lateral and posterior thigh region and the calf region in our patients using MRI evaluations. Thus, we diagnosed lipodystrophy in accordance with guidelines on the definitive criteria for the diagnosis of lipodystrophy $[2,11]$. If the patient has diabetes mellitus requiring high insulin doses, marked insulin resistance, severe hypertriglyceridemia, non-alcoholic steatohepatitis (NASH), or polycystic ovarian syndrome, lipodystrophy may be indicated. As shown in table 2, Patients 1 and 8 had relatively severe insulin resistance, Patient 6 had non-alcoholic fatty liver disease, Patient 12 had liver cirrhosis probably due to NASH, and Patient 14 had diabetes mellitus requiring high insulin doses. 
We diagnosed 15 female patients with PL from approximately 800 female patients; therefore, the prevalence of PL was calculated as approximately $1.9 \%$ in female patients at our diabetic patient clinic. On evaluating DEXA and MRI findings from these 15 women with PL, we identified subcutaneous fat loss in their lower limbs, frequently accompanied by excess subcutaneous fat in the trunk. They all had near-complete loss of subcutaneous fat, particularly in the anterolateral and posterior thigh region and the calf region. Subcutaneous fat loss in the gluteal regions and forearms was accompanied by fat loss in the lower limbs in some patients. Patient 10, the youngest patient, had normal glucose tolerance without insulin resistance. Subcutaneous fat in other regions may compensate for the metabolic dysfunction due to decreased fat in the lower limbs.

Of note, lower limb lean mass in the PL group was significantly lower compared with the control group. There were six PL patients (Patients 5, $7,8,9,11$, and 12) with lower limb lean mass less than mean-2SD of that of the Control 1 group. The decreased muscle mass in some diabetic patients is possibly caused by diabetic neuropathy, including autonomic dysfunction, poor blood supply due to obstructive arteriosclerosis, poor glycemic control in the long term, and diabetic amyotrophy [22]. It is conceivable that disability that impairs walking may be cause of the decreased muscle mass in the lower limbs. Because our patients in the present study had noticed no change in the size of their lower limbs since adolescence and exhibited no neurological symptoms, including muscle weakness, the decreased lean mass of lower limbs in these six patients was likely not caused by these factors. On the other hand, total lean mass and trunk lean mass in our patients were significantly higher compared with the control group. Garg reported that increased arm muscle mass, increased leg muscle mass, and increased trunk soft tissue mass in FPLD2 with DEXA were observed compared with a control group [23]. Although the precise mechanisms for this difference of lean mass in parts of body between our patients and patients with FPLD2 is unknown, decreased lower limb lean mass may be a feature of FPLD1.

We showed both FMR and modified FMR are useful for detecting Japanese women with PL. Considered that our patients with excess fat in the trunk were more frequent compared with patients with FPLD as reported by Valerio, et al [12], it is expected that FMR and modified FMR can be useful indicators to identify female Japanese patients with PL.

We found diabetes was diagnosed at a significantly younger age in our patients with PL than in our type 2 female diabetic outpatients without the phenotype of lipodystrophy (data not shown). Eleven patients likely had autosomal-dominant inherited lipodystrophy, according to interviews, so we thought they could possibly FPLD. Four of 15 patients (Patients 4, 6, 7, and 15) did not have a family history of lipodystrophy. Three patients (Patients 6, 7, and 15) did not have evidence of acquired partial lipodystrophy. Patient 4 had rheumatoid arthritis at the age of 20 years. Her rheumatoid arthritis had low activity, with negative C-reactive protein. She noticed a decreased amount of subcutaneous fat in her lower limbs at 14 years old, before the occurrence of rheumatoid arthritis, and had no other etiology to indicate acquired PL. Because we did not examine the fat distribution in family members of these patients without a family history of lipodystrophy using DEXA and MRI, it is still possible that they have PL. Therefore, these four patients may have FPLD or other forms of PL. Because the severity of insulin resistance was not so evident in our patients and we did not have a patient with PL with fat loss restricted to the calf region, the prevalence of female patients with PL of the limbs seemed to be lower in Japan than in a study conducted in a Turkish diabetic outpatient clinic $[5,6]$. However, some patients with PL of the limbs had near complete loss of subcutaneous fat, particularly in the antero-lateral and posterior region and calf region, which was similar our patients in the present study. The reason why insulin resistance in patients with $\mathrm{PL}$ of the limbs is more severe than in our patients is unknown.

Genetic mutations in LMNA, PPARG, PLIN1, CIDEC, LIPE, ADRA2, and AKT2 have been reported to be associated with FPLD [14]. Our patients with PL who underwent genetic analyses had neither mutations in candidate genes known to be associated with FPLD nor novel likely candidate causal genes, as shown in Results section.

The results of oral glucose tolerance tests showed the levels of insulin deficiency and insulin resistance in some affected patients were similar to those in type 2 diabetic patients, although others exhibited relatively severe insulin resistance (Table $\mathrm{S} 1$ ). Therefore, we treated them with drugs such as dipeptidyl peptidase 4 inhibitors, TZDs and glucagon-like peptide-1 (GLP-1) receptor agonists, and insulin. It has been reported that TZDs, GLP-1 receptor agonists, and sodium-glucose cotransporter 2 inhibitors, leptin replacement, and metabolic surgery are effective for treating lipoatrophic diabetes [24-30].

Guillin-Amarelle, et al. recently reported that FPLD1, also known as Kobberling-type, is usually autosomal dominant, but its genetic cause is unknown and is characterized by fat loss in the lower limbs with abdominal fat accumulation, a high rate of positivity for a family history (90\%), and metabolic disturbances [8]. In addition, they reported that decreased fat levels in the lower limbs in FPLD1 determine the severity of metabolic disturbances, including blood glucose levels and microvascular complications. The 15 patients with PL identified in our Japanese diabetic outpatient clinic had subcutaneous fat loss in their lower limbs, frequently accompanied by excess subcutaneous fat in the trunk. They also noticed fat loss during childhood or adolescence and 11 patients with PL likely had an autosomal dominant inheritance of lipodystrophy according to interview findings. Eight patients who received a genetic analysis had no mutations in candidate genes known to be associated with FPLD. Judging from these data, we thought these 8 patients fitted into the category of FPLD1. As 6 patients with PL who did not receive a genetic analysis had fat loss in the limbs, frequently accompanied by abdominal fat accumulation, a high rate of positivity for a family history, metabolic disturbance, we could speculate they also might have FPLD1. A recent study reported that there is a common polygenic contribution, shared in FPLD1 and women with low leg fat mass [31]. However, the exact genetic cause remains unknown. Therefore, when we have difficulty in diagnosing patients with incomplete fat loss with FPLD1based on DEXA and MRI findings, we need a novel exact diagnostic criteria in FPLD1, derived from the exact molecular mechanism of pathogenesis. Guillin-Amarelle, et al. also reported that the cut-off point of FMR and modified FMR was 1.3 (sensitivity $81 \%$, specificity $87 \%$ ) and 2.2 (sensitivity $89 \%$, specificity $78 \%$ ) in 98 patients with FPLD1, respectively. Of note, these values were almost identical to those in our study.

Overall, $57 \%$ and $50 \%$ of 14 patients with PL, in whom the mean duration of diabetes was 15.3 years, had diabetic retinopathy and nephropathy, respectively, while $75 \%$ and $50 \%$ of 8 patients who fitted into the category of FPLD1 by a genetic analysis, in whom the mean duration of diabetes was 16.4 years, had diabetic retinopathy and nephropathy, respectively. Thus, these data suggested that patients with PL, especially patients with FPLD1 might be predisposed to develop diabetic microvascular complications.

Seven of 15 patients had severe atherosclerosis, while five of 8 patients who fitted into the category of FPLD1 by a genetic analysis 
had severe atherosclerosis. Thus, patients with PL, especially patients with FPLD1 might be predisposed to develop severe atherosclerosis. $66.7 \%$ of our patients and $88 \%$ of 8 patients who fitted into the category of FPLD1by a genetic analysis had a visceral fat areas at the umbilical level of $100 \mathrm{~cm}^{2}$ or more, which was frequently accompanied by hypertriglyceridemia. Serum adiponectin levels were less than 5.1 $\mu \mathrm{g} / \mathrm{mL}$ in five patients, and $80 \%$ of our patients had hypertension. Taken together, atherogenic risk factors and other factors, including unidentified causative genes and chronic inflammation in visceral fat and epicardial fat, may be related to the development of atherosclerosis $[15,17,18,32-36]$.

As reported previously [15], liver cirrhosis in Patient 12 who fitted into the category of FPLD1 by a genetic analysis was probably caused by NASH. Half of our patients had diabetic nephropathy, including two patients with chronic renal failure. Recently, Guebre-Egziabher, et al. reported that ectopic lipid redistribution due to adipose tissue dysfunction may contribute to the progression of renal dysfunction in patients with chronic kidney disease [37]. It is conceivable that patients with PL might be predisposed to develop renal dysfunction through this mechanism.

Four of 15 patients had malignancy, while two of 8 patients who fitted into the category of FPLD1 by a genetic analysis had malignancy. We considered a number of underlying mechanisms in the development of cancer in patients with PL. It has been reported that the visceral adiposity was associated with cancer, correlated with ectopic fat deposition in participants $(n=3086)$ from the Framingham Heart Study [38]. It has been also reported that the incidence of extrahepatic cancer was higher than that of hepatocellular carcinoma in 312 Japanese patients with biopsy-proven non-alcoholic fatty liver disease [39]. Patient 12 who had liver cirrhosis, probably due to NASH, died of gastric cancer during follow-up. Therefore, a possible mechanism is that ectopic fat deposition due to adipose tissue dysfunction induces an inflammatory response in all organs, which plays an important role in promoting cancer development $[40,41]$. The levels of serum adiponectin are often low in patients with FPLD [42], and low levels of serum adiponectin are associated with cancer [43]. Therefore, another possible mechanisms is that low levels of serum adiponectin may be associated with malignancy in our patients. Recently, it has been reported that a polymerase delta 1 (POLD1) mutation is associated with PL, and the carriers with this POLD1 mutation are predisposed to develop cancers, particularly colorectal and endometrial cancers $[44,45]$. Therefore, we speculated that colon cancer may be caused by an unknown lipodystrophic gene in Patient 10, who had colon cancer at 35 years old, although we did not perform genetic analysis in Patient 10 .

The current study has several limitations. First, we diagnosed FPLD without genetic diagnosis. Therefore, there is the possibility that some patients we identified do not have FPLD and unknown acquired factors may have influenced lipodystrophic processes in our patients. Second, as we did not perform whole-exome sequencing in all patients; therefore, some patients may have mutations in candidate genes. Third, because we did not examine all patients in our diabetic outpatient clinic using DEXA and MRI, we could not obtain an accurate prevalence of patients with PL.

In conclusion, we found not a few patients of 15 patients with PL we identified might have FPLD1. Our findings supported the previous report from an American diabetic outpatient clinic that FPLD1 is more common than previously thought [7]. However, we think there is the possibility that these patients will be classified into different etiology in the future. Some patients with PL had severe atherosclerosis $[15,17,18,32-36]$ and may be predisposed to develop NASH [28]. In addition, low fat levels in lower limbs in FPLD1 are associated with poor control of blood glucose levels and development of microvascular complications [8]. Therefore, we should try to identify patients with PL, including FPLD1, earlier in order to achieve a favorable glycemic control and prevent the development of microvascular complications, atherosclerosis, and NASH. Although further study is required to confirm the association with malignancy in a larger number of patients with PL, these patients may need regular medical checks for the early detection of malignancy. Because FMR helped to diagnose female patients with PL, we should use this method to identify female patients with PL earlier in clinical practice. Because there are only a few reports on FPLD1 $[7,8,15,31]$, a consensus on FPLD1 has yet to be reached, but it was reported in the two review articles on lipodystrophy, published in 2016 that the prevalence of FPLD1 is extremely low [1,2]. Therefore, we believe this report describing patients with FPLD1, identified in a diabetic outpatient clinic might be valuable so that PL can be more widely recognized.

\section{Acknowledgements}

We thank Dr. Takashi Shiokawa and Dr. Masataka Takesada (Tanita Inc, Tokyo, Japan) for providing the DEXA data on healthy female employees of the Tanita Company.

\section{Disclosure}

The authors declare that they have no conflicts of interest.

\section{References}

1. Hussain I, Garg A (2016) Lipodystrophy syndromes. Endocrinol Metab Clin North Am 45: 783-797. [Crossref]

2. Brown RJ, Araujo-Vilar D, Cheung PT (2016) The diagnosis and management of lipodystrophy syndrome: a multi-society practice guideline. J Clin Endocrinol Metab 85: $1-14$.

3. Agarwal AK, Garg A (2006) Genetic basis of lipodystrophies and management of metabolic complications. Annu Rev Med 57: 297-311. [Crossref]

4. Garg A (2011) Clinical review: Lipodystrophies: genetic and acquired body fat disorders. J Clin Endocrinol Metab 96: 3313-3325. [Crossref]

5. Strickland LR, Guo F, Lok K, Garvey WT (2013) Type 2 diabetes with partial lipodystrophy of the limbs: a new lipodystrophy phenotype. Diabetes Care 36: $2247-$ 2253. [Crossref]

6. Demir T, Akinci B, Demir L (2016) Partial lipodystrophy of the limbs in a diabetes clinic setting. Primary care diabetes 10: 293-299. [Crossref]

7. Herbst KL, Purnell JQ, Tannock LR (2003) Kobberling Type of familial partial lipodystrophy. Diabetes care 26: 1819-1824.

8. Guillín-Amarelle C, Sánchez-Iglesias S, Castro-Pais A (2016) Type 1 familial partial lipodystrophy: Understanding the Köbberling syndrome. Endocrine 54: 411-421. [Crossref]

9. Misra A, Peethambaram A, Garg A (2004) Clinical features and metabolic and autoimmune derangements in acquired partial lipodystrophy: report of 35 cases and review of the literature. Medicine (Baltimore) 83: 18-34. [Crossref]

10. Adachi M, Asakura Y, Moroya K (2013) Abnormal adipose tissue distribution with unfavorable metabolic profile in five children following hematopoietic stem cell transplantation: A new etiology for acquired partial lipodystrophy. Clin Pediatr Endocrinol 22: 53-64. [Crossref]

11. Handelsman Y, Oral EA, Bloomgarden ZT (2013) The clinical approach to the detection of lipodystrophy an AACE consensus statement. Endocr Pract 19: 107-116.

12. Valerio CM, Zajdenverg L, Freitas JE (2012) Body composition study by dualenergy x-ray absorptiometry in familial partial lipodystrophy: finding new tools for an objective evaluation. Diabetology \& Metabolic Syndrome 4: 40-51. 
13. Bonnet E, Delpierre C, Sommet A, Marion-Latard F, Herve R, et al. (2005) Total body composition by DXA of 241 HIV-negative men and 162 HIV-infected men: proposal of reference values for defining lipodystrophy. J Clin Densitom 8: 287-292. [Crossref]

14. Freitas P, Santos AC, Carvalho D (2010) Fat mass ratio: An objective tool to define lipodystrophy in hiv-infected patients under antiretroviral therapy. Journal of clinical densitometry 13: 197-203. [Crossref]

15. Iwanishi M, Ito-Kobayashi J, Washiyama M, Kusakabe T, Ebihara K (2018) Clinical characteristics, phenotype of lipodystrophy and a genetic analysis of six diabetic japanese women with familial partial lipodystrophy in a diabetic outpatient clinic. Intern Med 57: 2301-2313. [Crossref]

16. Iwanishi M, Ebihara K, Kusakabe T (2009) Clinical characteristics and efficacy of pioglitazone in a Japanese diabetic patient with an unusual type of familial partial lipodystrophy. Metabolism 58: 1681-1687.

17. Iwanishi M, Ebihara K, Kusakabe T (2012) Premature atherosclerosis in a japanese diabetic patient with atypical familial partial lipodystrophy and hypertriglyceridemia. Intern Med 51: 2573-2579.

18. Iwanishi M, Ebihara K, Kusakabe T (2014) A case of primary intestinal follicular lymphoma and premature atherosclerosis in a japanese diabetic patient with atypical familial partial lipodystrophy. Intern Med 53: 851-858.

19. Tokunaga K, Matsuzawa Y, Ishikawa K, Tarui S (1983) A novel technique for the determination of body fat by computed tomography. Int J Obes 7: 437-445. [Crossref]

20. Nakamura Y, Kikugawa S, Seki S, Takahata M, Iwasaki N, et al. (2015) PCSK5 mutation in a patient with the VACTERL association. BMC Res Notes 8: 228. [Crossref]

21. Kanda Y (2013) Investigation of the freely available easy-to-use software 'EZR' for medical statistics. Bone Marrow Transplant 48: 452-458. [Crossref]

22. Dyck PJ, Windebank AJ (2002) Diabetes and non-diabetic lumbosacral radiculoplexus neuropathies: new insights into pathophysiology and treatment. Muscle Nerve. 25: 477491.

23. Ji H, Weatherall P, Adams-Huet B, Garg A (2013) Increased skeletal muscle volume in women with familial partial lipodystrophy, dunnigan variety. J Clin Endocrinol Metab 98: E1410-E1413.

24. Arioglu E, Duncan-Morin J, Sebring N, Rother KI, Gottlieb N, et al. (2000) Efficacy and safety of troglitazone in the treatment of lipodystrophy syndromes. Ann Intern Med 133: 263-274. [Crossref]

25. Oliveira J, Lau E, Carvalho D (2017) Glucagon-like peptide-1 analogues - an efficient therapeutic option for the severe insulin resistance of lipodystrophic syndromes: two case reports. J Med Case Rep 11: 12. [Crossref]

26. Kawara Y, Imai J, Sawada S (2017) Sodium-glucose cotransporter 2 inhibitors improves complications of lipodystrophy: a case report. Ann Intern Med Mar 166: 450451.

27. Moon HS, Dalamaga M, Kim SY, Polyzos SA, Hamnvik OP (2013) Leptin's role in lipodystrophic and nonlipodystrophic insulin-resistant and diabetic individuals. Endocr Rev 34: 377-412. [Crossref]

28. Chong AY, Lupsa BC, Gordon CP (2010) Efficacy of leptin therapy in the different forms of human lipodystrophy. Diabetologia 53: 27-35.
29. Ebihara K, Kusakabe T, Hirata M, Masuzaki H, Miyanaga F, et al. (2007) Efficacy and safety of leptin-replacement therapy and possible mechanisms of leptin actions in patients with generalized lipodystrophy. J Clin Endocrinol Metab 92: 532-541. [Crossref]

30. Melvin A, Adams C, Flanagan C (2017) Roux-en-Y Gastric Bypass Surgery in the management of Familial Partial Lipodystrophy Type 1. J Clin Endocrinol Metab 102 3616-3620. [Crossref]

31. Lotta LA, Gulati P, Day FR (2016) Integrative genomic analysis implicates limited peripheral adipose storage capacity in the pathogenesis of human insulin resistance. Nat. Genet 49: 17-26. [Crossref]

32. Joy T, Kennedy BA, Al-Attar S, Runt BK (2009) Predicting abdominal adipose tissue among women with familial partial lipodystrophy. Metabolism 58: 828-834.

33. Godoy-Matos AF, Valerio CM, Braganca JB (2015) Evaluation of epicardial adipose tissue in familial partial lipodystrophy. Diabetology\& Metabolic Syndrome 7: 29.

34. Iacobellis G, Mohseni M, Bianco SD, Banga PK (2017) Liraglutide causes large and rapid epicardial fat reduction. Obesity (Silver Spring) 25: 311-316. [Crossref]

35. Rheinheimer J, de Souza BM, Cardoso NS, Bauer AC, Crispim D (2017) Current role of the NLRP3 inflammasome on obesity and insulin resistance: A systematic review. Metabolism 74: 1-9. [Crossref]

36. Garg A (2000) Gender differences in the prevalence of metabolic complications in familial partial lipodystrophy (Dunnigan variety). J Clin Endocrinol Metab 85: 17761782. [Crossref]

37. Guebre-Egziabher F, Alix PM, Koppe L (2013) Ectopic lipid accumulation: A potential cause for metabolic disturbances and a contributor to the alteration of kidney function. Biochimie 95: 1971-1979.

38. Britton KA, Massaro JM, Murabito JM, Kreger BE, Hoffmann U, et al. (2013) Body fat distribution, incident cardiovascular disease, cancer, and all-cause mortality. $J$ Am Coll Cardiol 62: 921-925. [Crossref]

39. Seko Y, Sumida Y, Tanaka S, Taketani H, Kanemasa K, et al. (2015) Predictors of malignancies and overall mortality in Japanese patients with biopsy-proven nonalcoholic fatty liver disease. Hepatol Res 45: 728-738. [Crossref]

40. Grivennikov SI, Greten FR, Karin M (2010) Immunity, inflammation, and cancer. Cell 140: 883-899. [Crossref]

41. Thi HTH, Hong S (2017) Inflammasome as a therapeutic target for cancer prevention and treatment. J Cancer Prev 22: 62-73. [Crossref]

42. Haque WA, Shimomura I, Matsuzawa Y, Garg A (2002) Serum adiponectin and leptin levels in patients with lipodystrophies. J Clin Endocrinol Metab 87: 2395. [Crossref]

43. Dalamaga M, Diakopoulos KN, Mantzoros CS (2012) The role of adiponectin in cancer: a review of current evidence. Endocr Rev 33: 547-594. [Crossref]

44. Sasaki H, Yanagi K, Ugi S (2018) Definitive diagnosis of mandibular hypoplasia, deafness, progeroid features and lipodystrophy (MDPL) syndrome caused by a recurrent de novo mutation in the POLD 1 gene. Endocr J 65: 227-238. [Crossref]

45. Ferrer-Avargues R, Diez-Obrero V, Martin-Tomas E (2017) Characterization of a novel POLD1 missense founder mutation in a Spanish population. J Gene Med 19. [Crossref]

Copyright: (C2019 Iwanishi M. This is an open-access article distributed under the terms of the Creative Commons Attribution License, which permits unrestricted use, distribution, and reproduction in any medium, provided the original author and source are credited. 